\title{
NEW CAVE-DWELLING MISOPHRIOIDS (CRUSTACEA: COPEPODA) FROM BERMUDA
}

SA RSIA

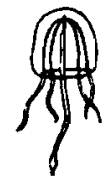

\author{
Geoffrey A. Boxshall \& Thomas M. Iliffe
}

Boxshall, Geoffrey A. \& Thomas M. Ilffe 198605 30. New cave-dwelling misophrioids (Crustacea: Copepoda) from Bermuda. - Sarsia 71:55-64.Bergen. ISSN 0036-4827.

\begin{abstract}
Two new misophrioid copepods are described from plankton taken from inland marine caves on Bermuda. A new genus and species, Speleophria bivexilla, is established on the basis of adult females from Roadside Cave and is distinguished from other misophrioids by the possession of a fused genital complex and a 2-segmented first leg endopod. The other new species, from Jane's Cave, is based on a single copepodid III stage and differs from other misophrioids in the segmentation of its mouthparts. It is not named because it cannot be placed in a genus until the adults are discovered.
\end{abstract}

Geoffrey A. Boxshall, Department of Zoology, British Museum (Natural History), Cromwell Road, London SW7 5BD, England. - Thomas $M$. Iliffe, Bermuda Biological Station for Research, Ferry Reach 1-15, Bermuda.

\section{INTRODUCTION}

The copepod order Misophrioida is of considerable phylogenetic interest because it represents the first branch to diverge from the main podoplean lineage within the Copepoda. It comprises seven species in five genera which together exhibit a suite of primitive characters close to those attributed to the ancestral copepod stock (BoxshaLL \& al. 1984). Six of these species are members of the near-bottom plankton community in the deep sea (BoxsHALL 1983; Alvarez 1985) but the seventh, Misophria pallida BoECK, inhabits the shallow neritic waters of Europe from Norway (SARS 1903), through to the Mediterranean and the Red Sea (GurNey 1927). The discovery of two new species from inland caves on Bermuda represents a major new habitat type for the Misophrioida. ILIFFE \& al. (1983) considered the biogeography of the crustacean fauna of more than 100 inland marine caves on Bermuda and indicated several possible routes of colonization. Troglobitic invertebrates of Tethyan age or with affinities to deep-sea taxa inhabit a marine lava tube cave in the Canary Islands (ILIFFE \& al. 1984). Similarly the newly described malacostracan order Mictacea has one species in Bermuda caves (Bowman \& IllFFE 1985) and another in deep ocean waters (SANDERS \& al. 1985). Misophrioids are essentially a deep-sea group (Boxshall 1984) and it is possible that they have been associated with Bermuda ever since it was formed about $100 \mathrm{Myr}$ BP, by volcanic eruption along the Mid-Atlantic Ridge (Reynolds \& AumenTo 1974).

Contribution No. 1073 of the Bermuda Biological Station for Research.

\section{THE SPECIES}

\section{Speleophria gen.n.}

D i a g n o s i s. Misophriidae. Prosome 5-segmented with carapace-like extension of maxillipedbearing somite only covering part of first pedigerous somite. Urosome of adult female 5-segmented, with genital complex formed by complete fusion of genital and first abdominal somites. Rostrum free, anteroventrally directed. Antennule indistinctly 22segmented. Antenna with 2-segmented endopod. Maxillulary praecoxa separated from coxa by conspicuous articulation. Legs 1 to 4 biramous, endopod of first leg 2-segmented, all other rami 3-segmented. Leg 5 uniramous, 4-segmented. Male unknown.

$\mathrm{T}$ y p e s p e c i e s. Speleophria bivexilla gen. et sp.n.

E $\mathrm{t}$ y $\mathrm{m}$ o l o $\mathrm{g}$ y. The generic name is derived from the Greek 'spelaion' meaning a cave.

Speleophria bivexilla gen. et sp.n.

H o l o t y p c. One female taken in Roadside Cave on 27 Sept. 1984. BM (NH) Registration number 1985.116.

$\mathrm{P}$ a r a t y p e s. Taken on 12 Nov. 1982 (4 우), 28 Aug. 1984 (3 of), 22 Sept. 1984 (1 O), and 27 Sept. 1984 (6 이) in Roadside Cave. Paratype Registration Nos 1985. $117-126$

E $\mathrm{t} \mathrm{y} \mathrm{mol}$ o $\mathrm{g} \mathrm{y}$. The specific name is derived from the Latin 'vexillum' meaning a streamer and alludes to the two pairs of large aesthetascs present on the antennules.

Type loca $1 \mathrm{it}$ y. All the specimens were taken from Roadside Cave, Hamilton Parish, Bermuda at depths from the surface to $5 \mathrm{~m}$, using hand held plankton nets with a mesh size of $93 \mu \mathrm{m}$. Roadside Cave is a small cave located in the 
Walsingham Tract of Bermuda, $110 \mathrm{~m}$ from the nearest enclosed inshore basin of Harrington Sound. The early Pleistocene age Walsingham formation is Bermuda's oldest limestone. It consists of a small entrance into a single room containing a saltwaterfilled fissure about $8 \mathrm{~m}$ long by $1 \mathrm{~m}$ wide and $6 \mathrm{~m}$ deep. The underwater fissure is floored with bare breakdown rubble. The water is very clear with no visible particles. Surface salinity and temperature in the pool were $32.53 \%$ and $19.9^{\circ} \mathrm{C}$ respectively, while at $1 \mathrm{~m}$ depth values of $32.93 \%$ and $20.5^{\circ} \mathrm{C}$ were recorded on 21 Sept. 1980, between two and four years prior to the collection of the misophrioids. Surface salinity varies with changes in rainfall. Tides in the pool are $57 \%$ of those in the open ocean with a lag of 80 minutes.

\section{Description of adult female}

(Figs 1-4)

Total body length of adult female (Fig. 1A) ranging from 375 to $408 \mu \mathrm{m}$, with a mean of $391 \mu \mathrm{m}$. Prosome large, 5-segmented but with first free thoracic somite partly concealed beneath a carapacelike extension from posterior margin of maxillipedbearing somite. Carapace better developed laterally than dorsally (see Fig. 4A). Nauplius eye absent. Conspicuous anteroventrally directed rostrum (Figs 1E, 4A) present. Lateral margin of dorsal cephalic shield not indented, cone organs absent. Last prosome somite capable of significant telescoping inside preceding somite. Urosome 5-segmented (Fig. 1B) with genital and first abdominal somites fused to form genital complex (Fig. 1C). Paired sensory setules present dorsally on second to fourth urosomites. Caudal rami slightly longer than wide and armed with 4 plumose setae of differing lengths along the posterior margin, a naked dorsal seta and a plumose lateral seta (Fig. 1B).

Antennule (Fig. 1E) 22-segmented and borne on an expanded basal pedestal which may represent a proximal antennulary segment. Armament elements as follows: I $-6+1$ aesthetasc, II-2, III-2, IV-1 +1 aesthetasc, V-1 + 1 aesthetasc, VI-1, VII-1, VIII-1, IX-1, X-1, XI-2, XII-1 + 1 aesthetasc, XIII-2 + 1 aesthetasc, XIV-1, XV-2, XVI-2, XVII-2, XVIII-2, XIX-1, XX-1, XXI-3 + 1 aesthetasc, XXII-5 + 2 aesthetascs. The aesthetascs present on the anteroventral surfaces of segments $I$ and $V$ are large and conspicuous even in whole mounts.

Labrum small, bilobed and not fused to rostrum.

Antenna (Fig. 2A) biramous; protopod comprising separate coxa and basis. Endopod 2-segmented; first segment with 3 setae subapically on outer margin, second segment with proximal cluster of 3 unequal setae on outer margin and 7 long distal margin setae. Exopod 6-segmented; segment 1 unarmed, segments 2 to 5 each with a long plumose seta on inner margin, segment 6 with 2 inner margin and 3 apical plumose setae.

Mandible (Fig. 2B) with well-developed gnathobase bearing several teeth along distal margin. Palp comprising basis, with a single inner margin seta, 2-segmented endopod and 5-segmented exopod. Endopod first segment with 1 inner seta, second with 4 distal margin setae. Exopod segment 1 unarmed, segments 2 to 4 each with 1 long inner margin plumose seta, segment 5 with 2 plumose setae.

Maxillule (Fig. 2C) with praecoxa and coxa separated by well developed articulation. Praecoxal arthrite bearing 10 setae around distal margin. Coxal exite represented by 6 unequal plumose setae located on outer margin; coxal endite well developed, bearing 2 curved spiniform elements and 2 setae. Basal endite produced medially, bearing a curved spiniform element and 4 setae. Basis and endopod apparently fused: incorporated first endopod segment armed with 3 setae at inner distal angle, second armed with 6 plumose distal margin setae. Exopod forming a flattened, 1-segmented plate armed with 8 plumose setae around its distal margin and with proximal fringes of setules on inner and outer margins.

Maxilla (Fig. 3A) 6-segmented. Praecoxa with 2 distal endites, the first bearing 6 setae, the second 3 setae. Coxa with 2 produced endites, the proximal bearing 3 and the distal 2 plumose setae. Basis with single endite produced into strong claw bearing 1 slender and 3 stout setae proximally. Ramus of 3 segments, each bearing a well developed inner margin seta, distal segment with 2 additional apical setae.

Maxilliped (Fig. 2D) 8-segmented. Long first segment representing syncoxa, bearing proximal, mid and distal endites armed with 2, 3, and 2 setae respectively. Basis with 3 inner margin setae. Ramus segment 1 with 2 inner margin setae, segments 2 to 5 with 1 each, segment 6 with 4 apical plumose setae.

Legs 1 to 4 (Fig. 3B-E) biramous with 3segmented exopods, endopod 2-segmented in leg 1 and 3-segmented in legs 2 to 4 . Spine and seta formula as follows.

\begin{tabular}{|c|c|c|c|c|}
\hline & coxa & basis & endopod & exopod \\
\hline $\operatorname{leg} 1$ & $0-1$ & $1-\mathrm{I}$ & $0-1 ; 1,5$ & $\mathrm{I}-0 ; \mathrm{I}-1 ; \mathrm{III}, \mathrm{I}, 3$ \\
\hline $\operatorname{leg} 2$ & $0-1$ & $1-0$ & $0-1 ; 0-2 ; \mathrm{I}, 5$ & I-1;I-1;III,I,4 \\
\hline $\operatorname{leg} 3$ & $0-1$ & $1-0$ & $0-1 ; 0-2 ; 1,5$ & I-1;I-1;III,I,4 \\
\hline $\operatorname{leg} 4$ & $0-1$ & $1-0$ & $0-1 ; 0-2 ; \mathrm{I}, 4$ & I-1;I-1;III,I,4 \\
\hline
\end{tabular}

Inner margins of proximal endopod segments with spinous processes at distal angles. Inner margins of proximal exopod segments with rows of pinnules. 


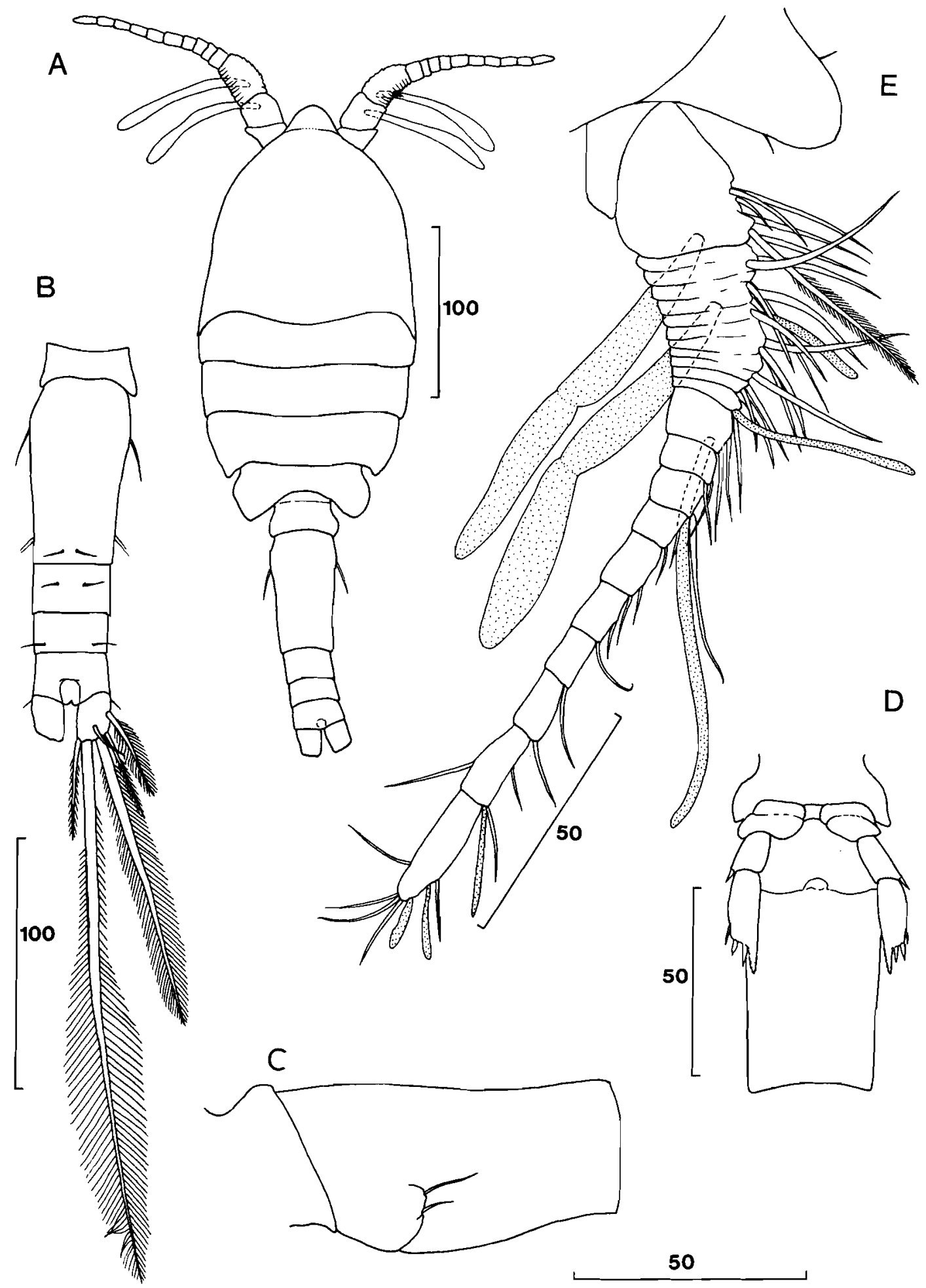

Fig. 1. Speleophria bivexilla gen. et sp.n., Female. A. Dorsal view. B. Urosome, dorsal. C. Genital complex, lateral. D. Same, ventral. E. Antennule and rostrum, dorsal. Scales in $\mu \mathrm{m}$. 


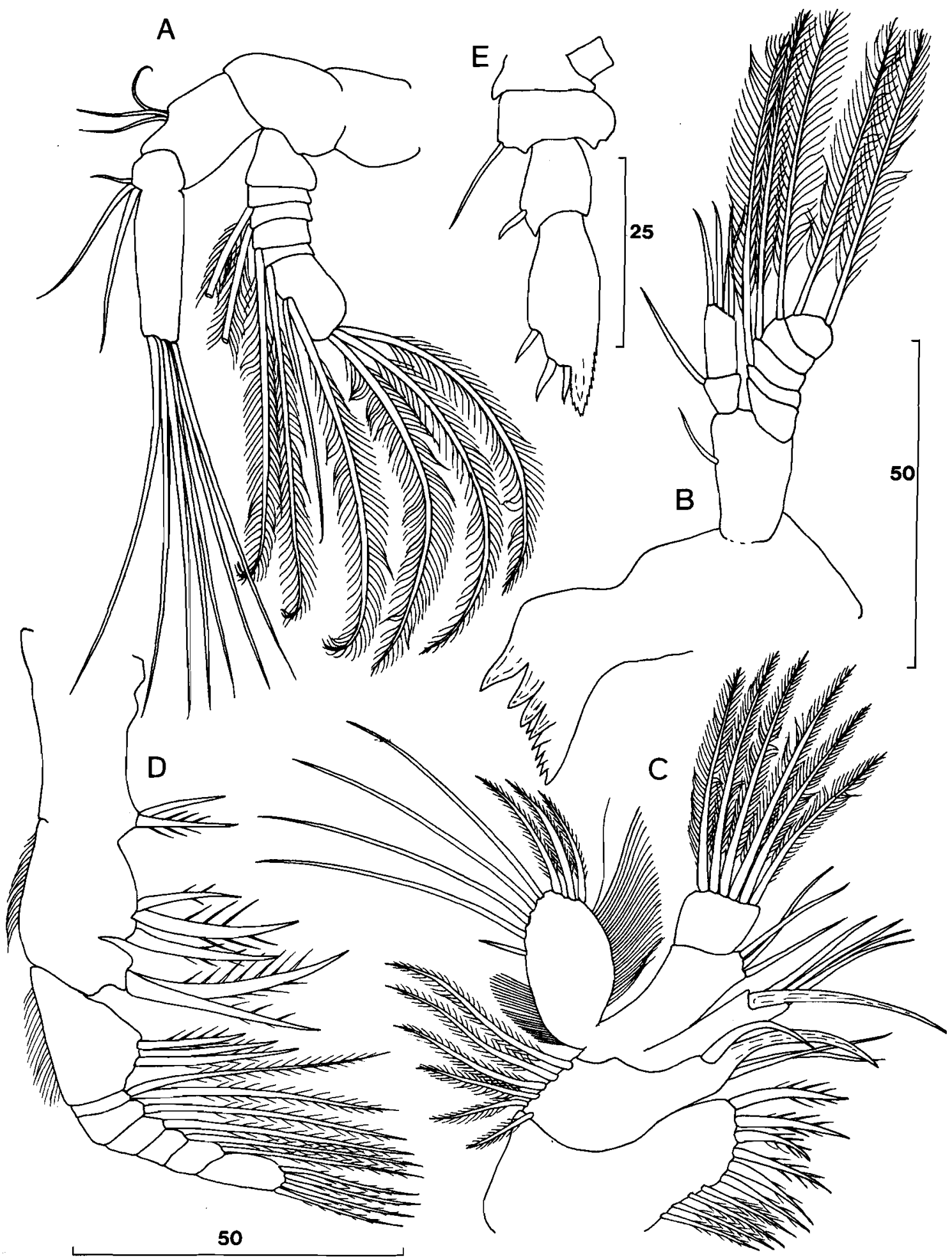

Fig. 2. Speleophria bivexilla gen. et sp.n., Female. A. Antenna, posterior. B. Mandible, anterior. C. Maxillule, anterior. $D$. Maxilliped, posterior. E. Leg 5 , ventral. Scales in $\mu \mathrm{m}$. 


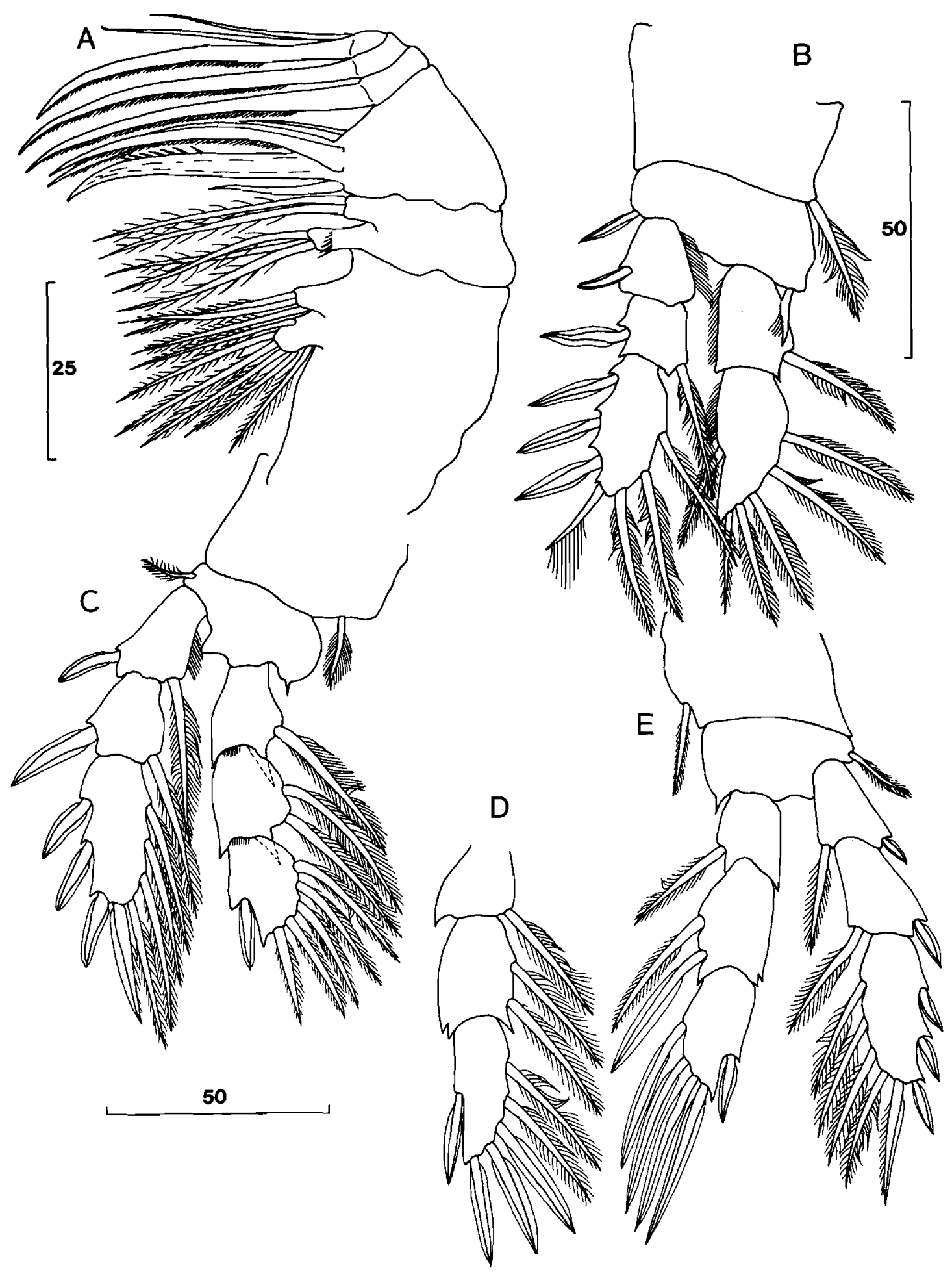

Fig. 3. Speleophria bivexilla gen. et sp.n., Female. A. Maxilla, anterior. B. Leg 1, anterior. C. Leg 2, anterior. D. Endopod of leg 3, anterior. E. Leg 4, anterior. Scales in $\mu \mathrm{m}$. 

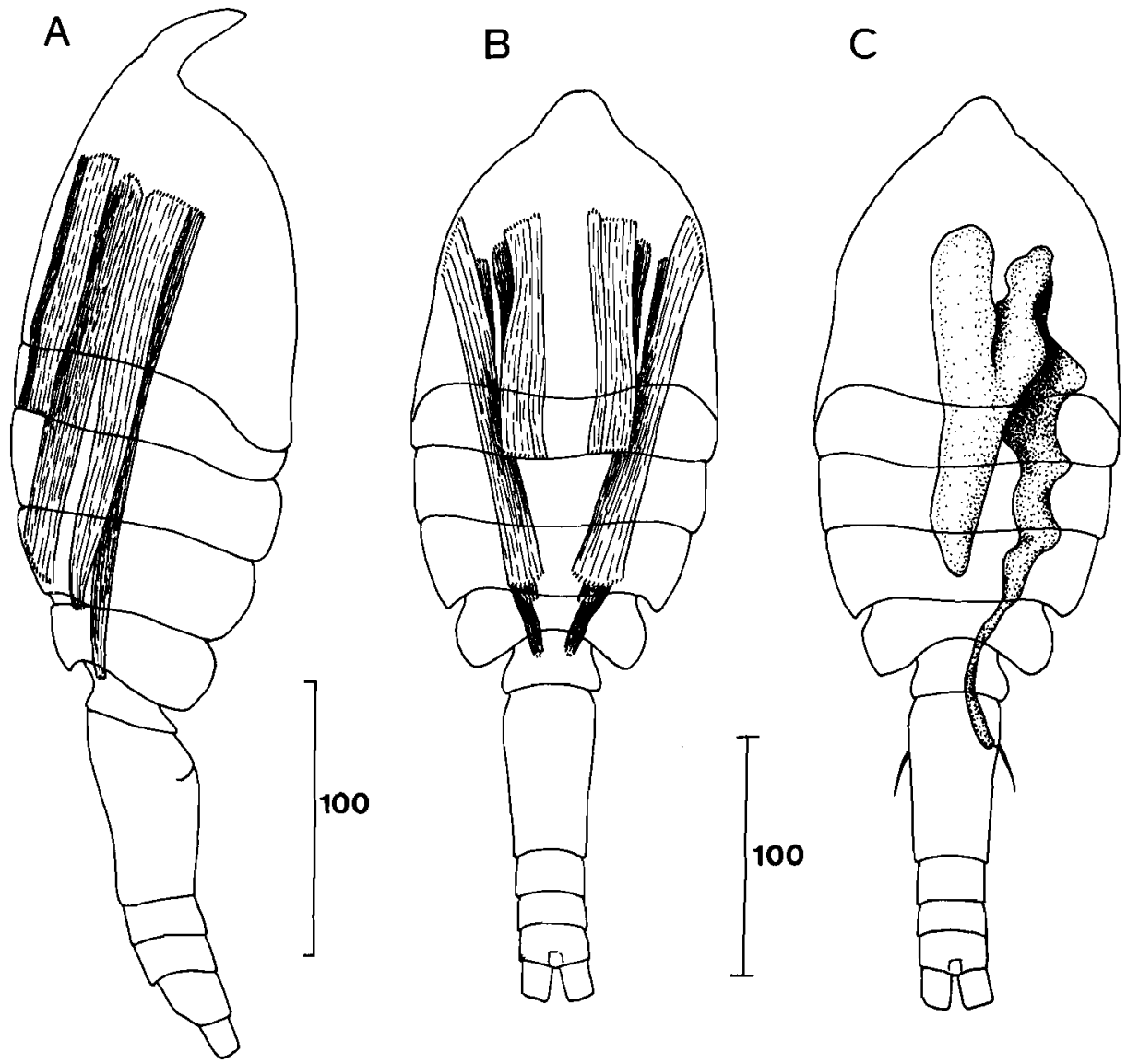

Fig. 4. Speleophria bivexilla gen. et sp.n., Female. A. Dorsal longitudinal trunk muscles in prosome, lateral. B. Same, dorsal. C. Female genital tract, dorsal. Scales in $\mu \mathrm{m}$.

All outer margin spines armed on both margins with hyaline membrane. Apical exopodal spines armed with pinnules on inner margin only, all other setae plumose, except some endopod setae on legs 3 and 4 which have strips of hyaline membrane.

Leg 5 (Fig. 2E) uniramous, with 4 segments representing coxa, basis and 2 -segmented exopod. Members of fifth leg pair joined by intercoxal sclerite as in legs 1 to 4 . Coxa unarmed, basis with outer plumose seta, exopod segment 1 with outer distal spine, segment 2 with 3 outer margin spines and an inner serrate spiniform process at the apex.

Leg 6 (Fig. 1C) represented by 2 unequal setae present on the operculum of each genital aperture.

The last prosome somite is capable of dorsal flexion by telescoping inside the preceding somite (Fig. 4A-B). This telescopic movement is produced by a bundle of the dorsal longitudinal trunk muscles which inserts on the anterior rim of the last prosome somite and is enhanced by the action of another bundle of the same muscles inserting on the dorsal surface of the preceding somite. The ventralmost bundle of dorsal trunk muscles inserts anterodorsally in the urosome and flexes it dorsally.

The new genus is unique amongst misophrioids in possessing an asymmetrical female reproductive system (Fig. 4C). There is a median ovary extending through most of the prosome. It may represent the fused paired ovaries. A single voluminous oviduct extends anteriorly from the midlateral surface of the ovary, curves ventrally, then passes posteriorly to its opening on that side of the genital complex. Nine females possessed full oviducts, visible through the body integument, of these 5 were on the right side as illustrated (Fig. 4C) and 4 were on the left.

\section{Remarks}

The new genus is readily distinguishable from all other misophrioids by the presence of a genital complex representing fused genital and first abdomi- 
nal somites. In other misophrioids these somites are separate. Another significant difference is the 2segmented endopod of the first swimming leg, as other known misophrioids have 3-segmented rami on all swimming legs. The mouthparts exhih:t the typical gnathostomatous condition of the order but the 2-segmented antennary endopod and the distinct articulation between the maxillulary praecoxa and coxa are noteworthy features. In the possession of a free rostrum and a 4-segmented uniramous fifth leg the new genus resembles Archimisophria BoxshaLL but these genera differ in urosome and leg segmentation as outlined above.

A most striking feature of the new species is the 2 pairs of long, strap-like aesthetascs on the antennules. These hang down from the anteroventral surface of the limb and presumably come into contact with the substratum as the copepod approaches it. They may provide chemosensory information of use in food location. This species is not adapted for gorging, as are some bathypelagic misophrioids (Boxshall 1984), since the carapace-like extension of the prosome is reduced so that it only partially covers the first pedigerous somite. The latter somite appears incapable of gross distension.

\section{Misophrioid copepodid III stage}

$\mathrm{M}$ a $\mathrm{t}$ e $\mathrm{r}$ i a l. The single specimen, a copepodid III, was taken on 2 Sept. 1984 in Jane's Cave, Hamilton Parish, Bermuda at a depth of $8-12 \mathrm{~m}$. It is deposited in the BM (NH) Registration No. 1985. 136.

Locality. Jane's Cave is located on the grounds of the Castle Harbour Hotel, about $300 \mathrm{~m}$ from Castle Harbour. Like most of Bermuda's caves it is situated in the Walsingham limestone formation. Jane's Cave is a large, complex cave consisting of two main fissure chambers separated by a central breakdown mound. Three saltwater pools occur at the base of the fissures. A pool near the entrance has soil spilling into it, while those farther into the cave contain bare breakdown blocks with only isolated deposits of finer sediments. Underwater stalactites and stalagmites, which only form in air, indicate that all known parts of the cave were dry during low sea stands corresponding to periods of Pleistocene glaciation. Water in the pools is very clear. On 21 Oct. 1980 , four years prior to collection of the copepod, surface salinity was $7.36 \%$ while at $1 \mathrm{~m}$ it was $25.39 \%$; surface and $1 \mathrm{~m}$ temperatures were $19.7^{\circ} \mathrm{C}$ and $20.7^{\circ} \mathrm{C}$ respectively. Tides in the cave have a range of $42 \%$ of those in the open sea and occur 110 minutes later.

\section{Description of the copepodid}

Total body length of copepodid III (Fig. 5A) 271 $\mu \mathrm{m}$. Prosome large, apparently 4-segmented but with first free thoracic somite entirely concealed beneath a carapace-like extension from the posterior margin of the maxilliped bearing somite. Nauplius eye absent. Rostrum a small, posteroventrally directed lobe, not visible in dorsal aspect and not fused to labrum. Urosome (Fig. 6F) 3-segmented. Caudal rami wider than long and armed with at least 5 elements, mostly broken, along outer and distal margins.

Antennules both broken off proximally. Antenna (Fig. 5B) biramous; protopod comprising fused coxa and basis armed with 2 long setae distally. Endopod 3-segmented; first segment with 1 inner angle seta, second with 2 short setae on inner margin and 3 long setae at inner distal angle, third with 1 naked and 5 plumose setae distally. Exopod 6-segmented; segments 2 to 5 each bearing an inner plumose seta, segment 6 with 2 plumose setae.

Mandible (Fig. 5C) with well developed gnathobase bearing several blades along its distal margin. Palp comprising basis, 2-segmented endopod and 5 -segmented exopod. Basis bearing an inner margin seta. Endopod with 2 setae on first segment and 4 distal plumose setae on second. Exopod segment 1 unarmed, segments 2 to 4 each with 1 inner plumose seta, segment 5 with 2 plumose setae.

Maxillule (Fig. 5D) with praecoxa and coxa incompletely separated. Praecoxal arthrite with 8 distal armature elements. Coxal exite represented by 6 unequal plumose setae located on outer margin; coxal endite with 3 apical setae. Basal endite bearing 2 long plumose setae and a short naked seta. Basis and endopod apparently fused; incorporated first endopod segment armed with 2 long plumose and 2 short naked setae distally, second segment with 3 setae midway along inner margin and 3 setae at inner distal angle, third segment separated by incomplete suture and bearing 3 apical plumose setae. Exopod forming a flattened, 1-segmented plate armed with 7 plumose setae along distal margin and a fringe of long setules along outer margin.

Maxilla (Fig. 5E) 6-segmented. Praecoxa with 2 bulbous distal endites, the first bearing 5 and the second 3 spinose setae. Coxa with 2 produced endites, the proximal bearing 2 and the distal 3 setae. Basis with a single endite produced into a strong claw bearing a single seta proximally. Ramus of 3 segments bearing a total of 6 long setae.

Maxilliped (Fig. 6A) 6-segmented. First segment representing syncoxa bearing proximal, mid and distal endites armed with 1,3 , and 2 spinose setae 


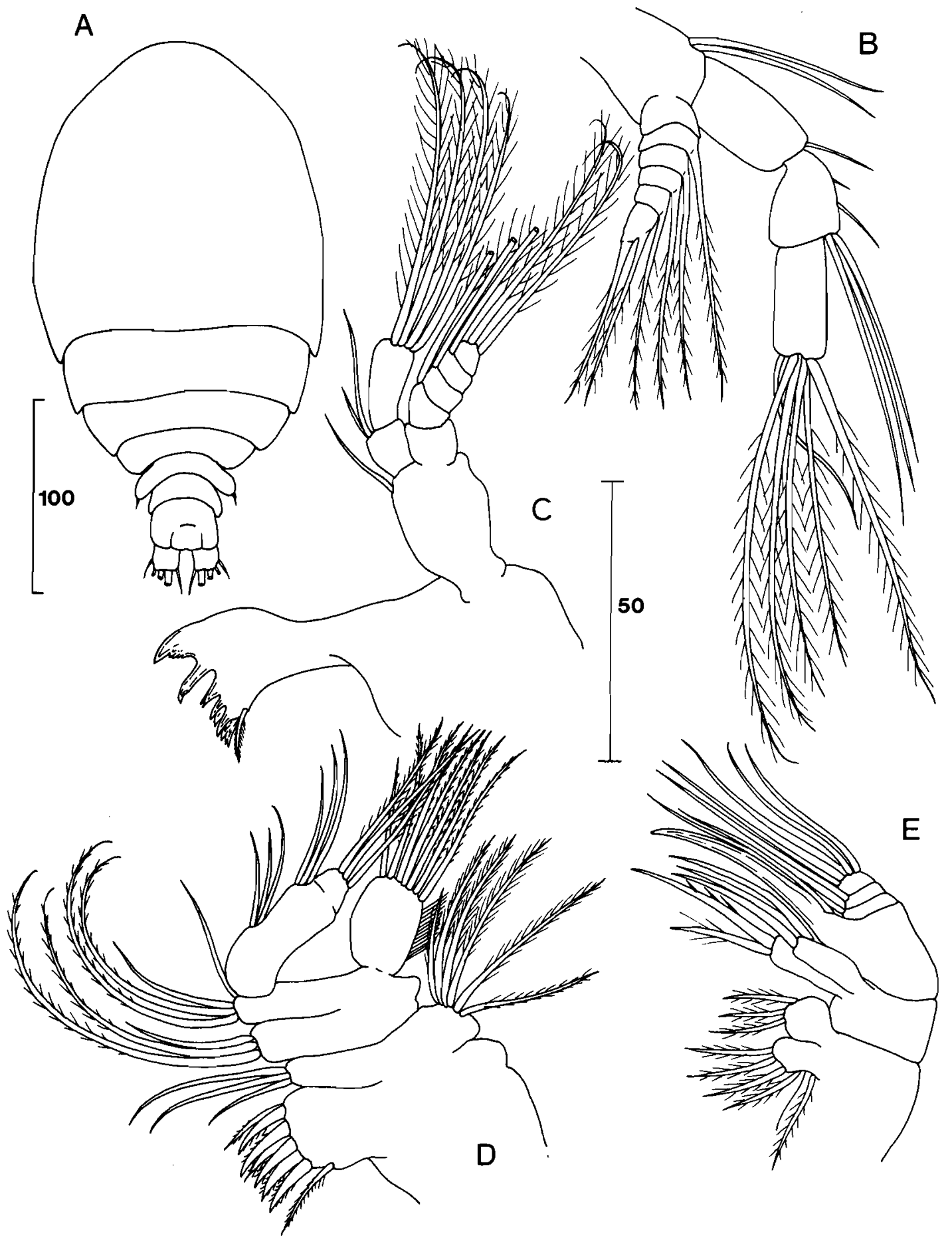

Fig. 5. Copepodid III stage of an unnamed species. A. Dorsal view. B. Antenna, anterior. C. Mandible, anterior. D. Maxillule, anterior. E. Maxilla, anterior. Scales in $\mu \mathrm{m}$. 


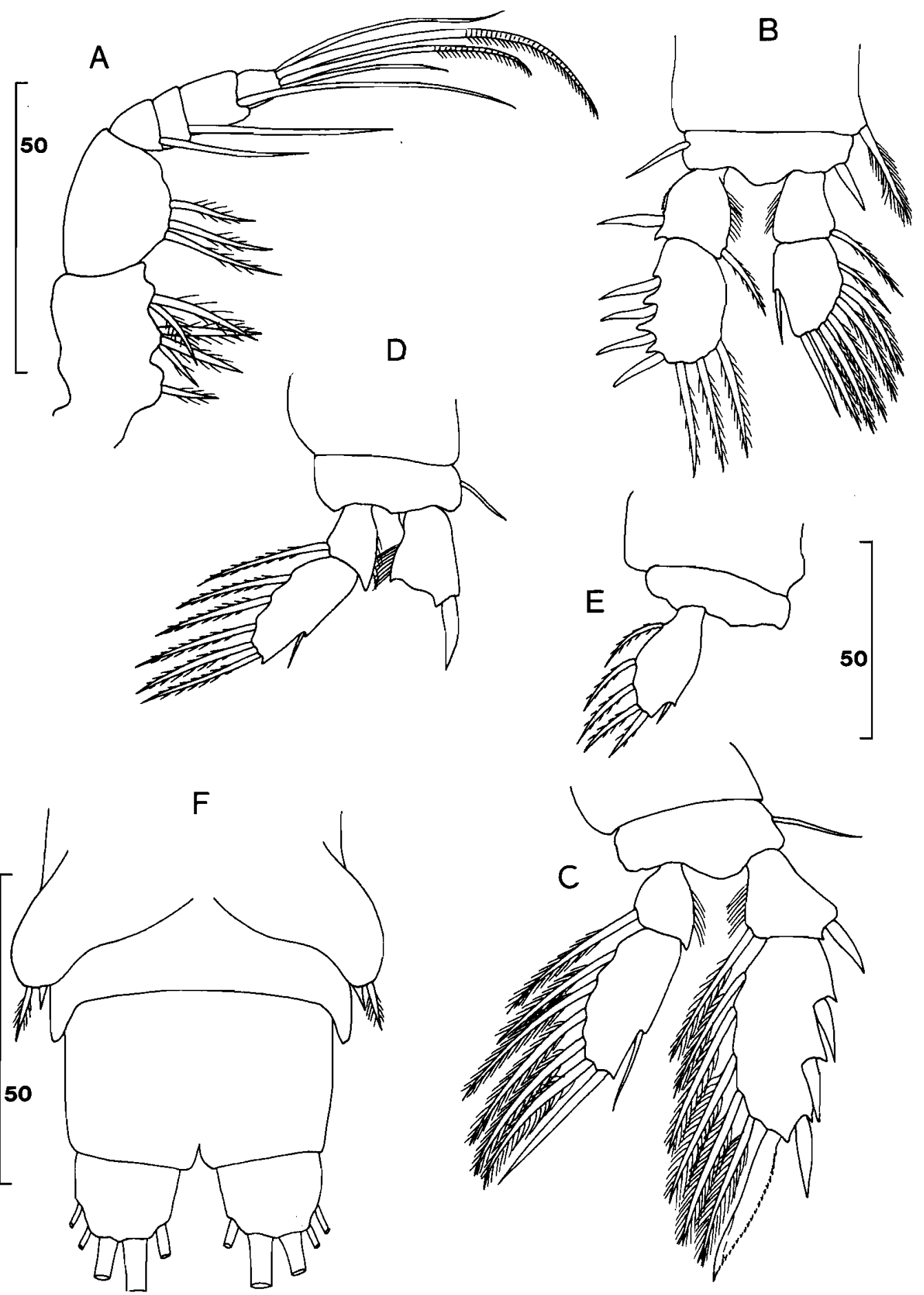

Fig. 6. Copepodid III stage of an unnamed species. A. Maxilliped, posterior. B. Leg 1, anterior. C. Leg 2, anterior. D. Leg 3, anterior. E. Leg 4, anterior. F. Urosome and leg 5, ventral. Scales in $\mu \mathrm{m}$. 
respectively. Basis with 3 inner margin plumose setae. Ramus segments 1 to 3 each with a single inner margin seta, segment 4 with 2 naked and 2 annulated plumose setae at apex.

Legs 1 to 4 (Fig. 6B-E) biramous. Rami 2segmented in legs 1 to 3 and 1-segmented in leg 4 . Spine and seta formula as follows.

\begin{tabular}{|c|c|c|c|c|}
\hline & coxa & basis & endopod & exopod \\
\hline $\operatorname{leg} 1$ & $0-1$ & $1-I$ & $0-1 ; 1, \mathbf{I}, 6$ & I-1;III ,I, 3 \\
\hline g 2 & $0-?$ & $1-0$ & $0-1 ; 1, \mathbf{I}, 5$ & I-1;III,I,5 \\
\hline & $0-$ ? & $1-0$ & $0-1 ; 1,1,4$ & $\mathrm{I}-? ;$ missing \\
\hline g 4 & $0-$ ? & $?-0$ & $1,1, \dot{4}$ & missing \\
\hline
\end{tabular}

Leg 5 (Fig. 6F) represented by subtriangular element, meeting in ventral midline, armed with 2 unequal apical elements.

\section{Remarks}

The key to known misophrioids (Boxshall 1983) utilises mainly features of antennule segmentation and fifth leg structure to separate species and genera, both of which are unknown for this copepodid. However, the mouthparts of the copepodid III of Benthomisophria palliata SARS are essentially the same as those of the adult (Boxshall \& ROE 1980) which indicates that valid comparisons can be made between the mouthparts of this copepodid and those of adult misophrioids. This copepodid can be distinguished from all other misophrioids on the basis of the segmentation of its mouthparts. The combination of a 6-segmented antennary exopod and 6segmented maxilliped does not occur in any other species of misophrioid. In addition, annulated setae on the maxilliped are known only from Misophriella tetraspina BoxshaLL which possesses 3 of them compared to only 2 in the copepodid described above.

Comparison with $S$. bivexilla from Roadside $\mathrm{Ca}$ ve, also on Bermuda, reveals many differences, particularly in rostrum configuration and in the extent of the carapace-like extension of the maxilliped bearing somite. In these features the copepodid more closely resembles Misophriopsis dichotoma BoxSHALL, known only from $3000 \mathrm{~m}$ in the North Atlantic off the Azores. This copepodid from Jane's Cave clearly represents a new species but it cannot be placed either in an existing genus or a new genus until the adult stages are found. A close relationship to Speleophria, known from Roadside Cave, seems unlikely however.

\section{ACKNOWLEDGEMENTS}

This work is part of a faunal survey of Bermuda caves funded by a National Science Foundation grant (BSR 8215671 ) to T.M. Iliffe. We thank Mary van Soeren and Robert Power for assistance with cave diving investigations and collection of specimens. We also extend special appreciation to Dr Audun Fosshagen for assistance with collecting and sorting the specimens, and for his comments on the manuscript.

\section{REFERENCES}

Alvarez. M.P.J. 1985. A new species of misophrioid copepod from the near-bottom waters off Brazil. J. nat. Hist. 19:953-959.

Bowman, T.E. \& T.M. Iliffe. 1985 Mictocaris halope, a new unusual peracaridan crustacean from marine caves on Bermuda. - J. Crust. Biol. 5:58-73.

Boxshall, G.A. 1983. Three new genera of misophrioid copepods from the near-bottom plankton community in the North Atlantic Ocean. - Bull. Br. Mus. nat. Hist. (Zool.). 44:103-124.

- 1984. The functional morphology of Benthomisophria palliata Sars, with a consideration of the evolution of the Misophrioida. - Crustaceana, Suppl. 7:32-46.

Boxshall, G.A., F.D. Ferrari, \& H. Tiemann. 1984. The ancestral copepod: towards a consensus of opinion at the First International Conference on Copepoda 1981. - Crustaceana, Suppl. 7:68-84.

Boxshall, G.A. \& H.S.J. Roe. 1980. The life history and ecology of the aberrant bathypelagic genus Benthomisophria Sars, 1909 (Copepoda: Misophrioida). Bull. Br. Mus. nat. Hist. (Zool.), 38:9-41.

Gurney, R. 1927. Zoological Results of the Cambridge Expedition to the Suez Canal, 1924. XXXIII. Report on the Crustacea: - Copepoda (Littoral and Semi-parasitic). - Trans. zool. Soc. Lond. 22: 451-577.

Iliffe, T.M., C.W. Hart Jr. \& R. B. Manning. 1983. Biogeography and the caves of Bermuda - Nature. 302:141-142.

Iliffe, T.M., H. Wilkens, J. Parzefall, \& D. Williams. 1984. Marine lava cave fauna: Composition, biogeography, and origins. - Science. 225:309-311.

Reynolds, P.H. \& F. Aumento. 1974. Deep Drill 1972. Potassium-Argon Dating of the Bermuda Drill Core. - Can. J. Earth Sci. 11:1269-1273.

Sanders, H.L., R.R. Hessler, \& S.P. Garner. 1985 Hirsutia bathyalis, a new unusual deep-sea benthic peracaridan crustacean from the tropical Atlantic. - $J$. Crust. Biol. 5:30-57.

Sars, G.O. 1903. An account of the Crustacea of Norway. V. Copepoda Harpacticoida. - Bergen Museum. Pts I-II : $1-28$.

Accepted 18 October 1985. 